\title{
Patients' Survival Expectations With and Without Their Chosen Treatment for Prostate Cancer
}

Jinping $X u, M D, M S^{1}$

James Janisse, $P b D^{1}$

Julie J. Ruterbusch, MPH

Joel Ager, $P b D^{1}$

Joe Liu, $M D^{3}$

Margaret Holmes-Rovner, $\mathrm{PbD}^{4}$

Kendra L. Schwartz, MD, MSPH

'Department of Family Medicine and Public Health Sciences, Wayne State University,

Detroit, Michigan

${ }^{2}$ Department of Oncology, Wayne State University, Detroit, Michigan

${ }^{3}$ Department of Anesthesiology, Wayne State University, Detroit, Michigan

${ }^{4}$ Department of Medicine, Michigan State University, East Lansing, Michigan

\begin{abstract}
PURPOSE Overtreatment of screen-detected localized prostate cancer (LPC) is an important public health concern, since the survival benefit of aggressive treatment (surgery or radiation) has not been well established. We investigated the survival expectations of patients who had LPC with and without their chosen treatment.
\end{abstract}

METHODS A population-based sample of 260 men (132 black, 128 white) 75 years old or younger with newly diagnosed LPC completed a self-administered survey. How long the patients expected to live with their chosen treatment, how long they would expect to live with no treatment, and factors associated with the difference in perceived life expectancy were assessed using multivariable analysis.

RESULTS Without any treatment, 33\% of patients expected that they would live less than 5 years, $41 \% 5$ to 10 years, $21 \% 10$ to 20 years, and $5 \%$ more than 20 years. With their chosen treatment, $3 \%$ of patients expected to live less than 5 years, $9 \% 5$ to 10 years, 33\% 10 to 20 years, and 55\% more than 20 years. Treatment chosen, age, general health perception, and perceived cancer seriousness predicted the differences in perceived life expectancy, while race and actual tumor risk did not. After adjustment for other covariates, men who choose surgery or radiation expected greater gain in survival than men who chose watchful waiting or active surveillance.

CONCLUSIONS Most patients with LPC underestimated their life expectancy without treatment and overestimated the gain in life expectancy with surgery or radiation. These unrealistic expectations may compromise patients' ability to make informed treatment decisions and may contribute to overtreatment of LPC. Primary care physicians, when included in the decision process, should focus on helping patients develop realistic expectations and choices that support their treatment goals.

Ann Fam Med 2016;14:208-214. doi: 10.1370/afm.1926.

\section{INTRODUCTION}

$\mathrm{D}$ ue to the growing concerns about overtreatment of localized prostate cancer (LPC), practice guidelines now include observationthat is, watchful waiting or active surveillance (WW/AS) — as an appropriate initial management strategy for low-risk LPC., Observation, however, is used for only about $10 \%$ to $20 \%$ of patients. ${ }^{3-6}$ Moreover, aggressive treatment of LPC, including low-risk LPC, is increasing., ${ }^{4,7}$

Although new technology may be a reason men choose aggressive treatment, anxiety and fear of cancer progression is often cited as the reason for the low uptake of observation. ${ }^{8-11}$ Yet the survival benefit of aggressive treatment (ie, surgery or radiation) for LPC has not been demonstrated in a PSA-screened population. In fact, the Prostate Cancer Intervention Versus Observation Trial (PIVOT) showed that surgery did not significantly reduce all-cause or prostate-cancer-specific mortality as compared with observation through a median of 10 years of follow-up. ${ }^{12}$

To make informed treatment decisions, patients with LPC need a realistic understanding of the likely benefits and harms of each treatment option. Few studies, however, have examined patients' expectations of sur-
Jinping Xu, MD, MS

3939 Woodward Ave, 3nd Floor

Detroit, MI 48021

jxu@med.wayne.edu 
vival with aggressive treatment for LPC. We identified only 1 previous study, and it suggested that patients with LPC grossly overestimate the survival benefit of aggressive treatment. ${ }^{13}$ This study was conducted in a single private practice and included mostly white, well-educated men. The prevalence and determinants of this misunderstanding have not been characterized. More important, there is a paucity of research in prostate cancer treatment decision-making and survival expectations that includes enough black men. Research is needed to determine whether racial differences in survival expectations contribute to the observed racial differences in LPC treatment patterns and outcomes. ${ }^{14}$

Using a racially and socioeconomically diverse population-based sample of men with newly diagnosed LPC, we sought to characterize the self-reported survival expectations of patients who chose 1 of 3 main types of treatment options (surgery, radiation, or observation). In addition, we sought to identify the demographic, tumor characteristic, and sociocultural factors associated with reported survival expectations with and without the patients' chosen treatments.

\section{MATERIALS AND METHODS}

We conducted a cross-sectional survey of black and white men living in the metropolitan Detroit area aged 75 years or younger and newly diagnosed with LPC between 2009 and 2010. A detailed report of the study method, sampling, and survey instrument has been previously reported. ${ }^{5}$ Briefly, new LPC cases were identified by Rapid Case Ascertainment (RCA) in the Metropolitan Detroit Cancer Surveillance System (MDCSS). If the patient's physician stated that the patient was healthy enough to participate, the eligible patient was mailed a self-administered survey. The Dillman method was used to encourage survey response. ${ }^{15} \mathrm{LPC}$ was defined as T1 to T2 tumors based on American Joint Committee on Cancer (AJCC) stage criteria. The study received approval from the institutional review board at Wayne State University, Detroit, Michigan.

\section{Sampling}

During the study period, a total of 874 potentially eligible patients with LPC were identified. To achieve similar numbers of white and black men, white men were sampled at a ratio of 1:3, leaving a total of 559 men sampled for study contact. After initial physician and patient contact, 168 total patients were excluded from the study (118 because their physicians did not approve their participation and 50 because they did not meet all study inclusion criteria), resulting in 391 eligible patients to be surveyed. ${ }^{5}$

\section{Survey Instrument}

The content and design of the survey were based on a thorough literature review and refined by the findings of qualitative studies. ${ }^{8,16}$ The survey asked men to report their treatment choice, reasons for the choice, and what treatment options were offered and recommended by their physicians. ${ }^{5}$ In addition, patients were asked the following 2 questions: "How long do you expect you would live without any treatment for your prostate cancer?" and "How long do you expect you would live with your treatment of choice for your prostate cancer?" The possible responses to both questions were grouped into 4 categories: fewer than 5 years, 5 to 10 years, 10 to 20 years, and more than 20 years.

\section{Measures}

The primary outcome variable was patient's selfreported life expectancy (LE) with and without their treatment of choice. Numeric midpoints were used to represent the categories in analyses. Difference in perceived LE with the chosen treatment compared with no treatment was calculated by taking the difference between the 2 LE measures. The primary predictor variable was the patient's self-reported chosen treatment (surgery, radiation, or WW/AS). Other predictor variables considered were age, race, education, general health, cancer risk level, perceived cancer seriousness, worry about cancer, and the number of self-reported co-morbidities, categorized using a modified Charlson comorbidity index. ${ }^{17}$ Cancer risk level was categorized as low, intermediate, or high risk using the widely accepted D'Amico criteria, ${ }_{1}^{1}$ which use prostate-specific antigen (PSA), Gleason score, and clinical stage. ${ }^{1,18}$

\section{Statistical Analysis}

Initial analyses assessed the bivariate relationships between study variables and treatment choice and between study variables and each of the 3 LE measures: (1) perceived LE without treatment ${ }_{i}(2)$ perceived LE with chosen treatment ${ }_{i}$ (3) the difference between the 2. Demographic variables across treatment groups were compared using ANOVA for continuous variables and $\chi^{2}$ for categorical variables. To compare perceived LE and change in perceived LE, $t$-tests and ANOVA were used for categorical variables and Pearson correlations for continuous variables. To determine whether treatment choice is associated with perceived differences in LE, multiple linear regression analysis was used where the outcome was the difference in perceived LE, and predictors included treatment choice and other study variables related to the difference in LE. To maximize the number of patients included, multiple imputation methods were employed to handle missing data. $P$ values of .05 or less were considered 
significant, and all analyses were completed using SPSS version 22 (IBM Corporation).

\section{RESULTS}

Of the 391 eligible patients, 266 completed the survey, for a response rate of $68 \%$ (white $78 \%$, black $62 \%$ ). Six men were excluded from data analysis because 4 reported a race other than black or white and 2 had extensive missing data. Another 12 men were excluded from multivariable regression analysis because they had selected a treatment other than the 3 main treatments (ie, surgery, radiation, WW/AS), and 8 were excluded because they were still undecided about treatment. ${ }^{5}$ At the time of survey, 2/3 of the men had started or completed their chosen treatment. Compared with non-responders, responders were younger (60.7 vs 62.6 years, $P=.03)$ and had lower PSA levels (6.9 vs $10.5, P=.01)$ but had similar Gleason scores ( 6.78 vs $6.88, P=.36)$ and similar treatment distribution $(P>.05)$.

Table 1 presents patient demographic, psychosocial, and tumor characteristics by the 3 major treatment groups. Men in the surgery group were younger, with better self-reported general health and fewer comorbidities than men in radiation and WW/ AS groups (Table 1). While PSA level did not differ among treatment groups, men in the surgery group had a higher proportion of tumors with Gleason score of 7 or more, and/or stage T2c or higher. The surgery group also perceived their cancer as more serious and worried more about it than men in other groups. There were no significant differences in race or education among the groups.

Figure 1 illustrates patients' perceived LE without treatment and with the treatment of choice. Without any treatment, 33\% of men expected to live less than 5 years and only $5 \%$ beyond 20 years, in contrast, with their chosen treatment, only $3 \%$ of men expected to live less than 5 years, and $55 \%$ expected to live beyond 20 years. In the bivariate correlation analysis, perceived cancer seriousness, not the actual cancer risk, was the only variable associated with estimated $\mathrm{LE}$ without treatment $(r=-0.161, P<.05)$. Two variables, age $(r=-0.326, P<.01)$ and general health $(r=0.193, P<.01)$, were associated with estimated LE with the chosen treatment.

Table 2 compares perceived difference in LE between treatment groups in unadjusted and adjusted
Table 1. Patient Demographics and Tumor Characteristics by Treatment Choice ( $N=240$ )

\begin{tabular}{|c|c|c|c|c|}
\hline Variable & $\begin{array}{l}\text { Surgery } \\
n=137\end{array}$ & $\begin{array}{c}\text { Radiation } \\
n=72\end{array}$ & $\begin{array}{l}\text { WWIAS } \\
\mathrm{n}=31\end{array}$ & $\begin{array}{c}P \\
\text { value }\end{array}$ \\
\hline Age, mean (SD) & $59.4(7.4)$ & $63.2(7.2)$ & $64.3(7.9)$ & $<.001$ \\
\hline Age group, No. (\%) & & & & .002 \\
\hline$\leq 65$ & $102(74.5)$ & $41(56.9)$ & $14(45.2)$ & \\
\hline$>65$ & $35(25.5)$ & $31(43.1)$ & $17(54.8)$ & \\
\hline Race, No. (\%) & & & & .81 \\
\hline Black & $68(49.6)$ & $36(50.0)$ & $17(54.8)$ & \\
\hline White & $69(50.4)$ & $36(50.0)$ & $14(45.2)$ & \\
\hline Education, No. (\%) & & & & .70 \\
\hline$\leq$ High school & $46(34.1)$ & $25(35.2)$ & $11(35.5)$ & \\
\hline Some college & $37(27.4)$ & $27(38.0)$ & $10(32.3)$ & \\
\hline College graduate & $27(20.0)$ & $11(15.5)$ & $5(16.1)$ & \\
\hline $\begin{array}{l}\text { Some postgraduate } \\
\text { study }\end{array}$ & $25(18.5)$ & $8(11.3)$ & $5(16.1)$ & \\
\hline $\begin{array}{l}\text { No. comorbidities, } \\
\text { mean (SD) }\end{array}$ & $1.23(1.0)$ & $1.75(1.3)$ & $1.39(1.0)$ & .01 \\
\hline $\begin{array}{l}\text { General health percep- } \\
\text { tion, mean (SD) }\end{array}$ & $2.71(0.84)$ & $2.41(0.89)$ & $2.26(0.89)$ & .008 \\
\hline $\begin{array}{l}\text { Perceived cancer seri- } \\
\text { ousness, mean (SD) }\end{array}$ & $3.8(1.3)$ & $3.1(1.3)$ & $2.9(1.4)$ & $<.001$ \\
\hline $\begin{array}{l}\text { Worry about prostate } \\
\text { cancer, mean (SD) }\end{array}$ & $2.5(1.0)$ & $2.1(0.9)$ & $2.4(1.0)$ & .004 \\
\hline PSA level, No. (\%) & & & & .39 \\
\hline$\leq 4$ & $36(26.9)$ & $22(31.0)$ & 8 (28.6) & \\
\hline $5-9$ & $80(59.7)$ & $41(57.7)$ & $15(53.6)$ & \\
\hline $10-19$ & $15(11.2)$ & $4(5.6)$ & $5(17.9)$ & \\
\hline$\geq 20$ & $3(2.2)$ & $4(5.6)$ & $0(0.0)$ & \\
\hline Gleason score, No. (\%) & & & & .03 \\
\hline$\leq 6$ & $48(35.3)$ & $30(46.2)$ & $15(50.0)$ & \\
\hline 7 & $79(58.1)$ & $25(38.5)$ & $11(36.7)$ & \\
\hline $8-10$ & $9(6.6)$ & $10(15.4)$ & $4(13.3)$ & \\
\hline Stage, No. (\%) & & & & $<.001$ \\
\hline$\leq \mathrm{T} 2 \mathrm{a}$ & $21(15.4)$ & $51(78.5)$ & $23(76.7)$ & \\
\hline T2b or T2NOS & $19(14.0)$ & $8(12.3)$ & $5(16.7)$ & \\
\hline$\geq \mathrm{T} 2 \mathrm{c}$ & $96(70.6)$ & $6(9.2)$ & $2(6.7)$ & \\
\hline Risk level, No. (\%) & & & & $<.001$ \\
\hline Low risk & $8(5.9)$ & $26(40.0)$ & $9(30.0)$ & \\
\hline Intermediate risk & $29(21.3)$ & $23(35.4)$ & $15(50.0)$ & \\
\hline High risk & $99(72.8)$ & $16(24.6)$ & $6(20.0)$ & \\
\hline \multicolumn{5}{|c|}{ PSA = prostate-specific antigen; W/W/AS = watchful waiting or active surveillance. } \\
\hline $\begin{array}{l}\text { Note: The general health } p \\
\text { ness scale ranged from } 1 \text { ( } \\
\text { ranged from } 1 \text { (Not at all) }\end{array}$ & $\begin{array}{l}\text { Is scale ranged } \mathrm{fr}_{\mathrm{r}} \\
\text { Serious) to } 5 \text { (Ve } \\
\text { y Much). }\end{array}$ & $\begin{array}{l}\text { (Poor) to } 5 \text { (Ex } \\
\text { tious), and the }\end{array}$ & $\begin{array}{l}\text { the perceived ca } \\
\text { pout prostate can }\end{array}$ & $\begin{array}{l}\text { r serious- } \\
\text { scale }\end{array}$ \\
\hline
\end{tabular}


analyses. Men who chose aggressive treatment, either surgery or radiation, expected to live on average more than 11 years longer than with no treatment, and their perceived life expectancy was 4 years longer than that of men who chose WW/AS. There were no significant differences between men who chose surgery and those who chose radiation in perceived years gained. After adjusting for covariates, men who chose WW/ AS estimated longer LE without treatment and shorter LE with their treatment than men who chose surgery or radiation (Figure 2 and Table 2). Therefore, the per-

Figure 1. Perceived survival expectations without treatment and with treatment of choice $(n=229)$.

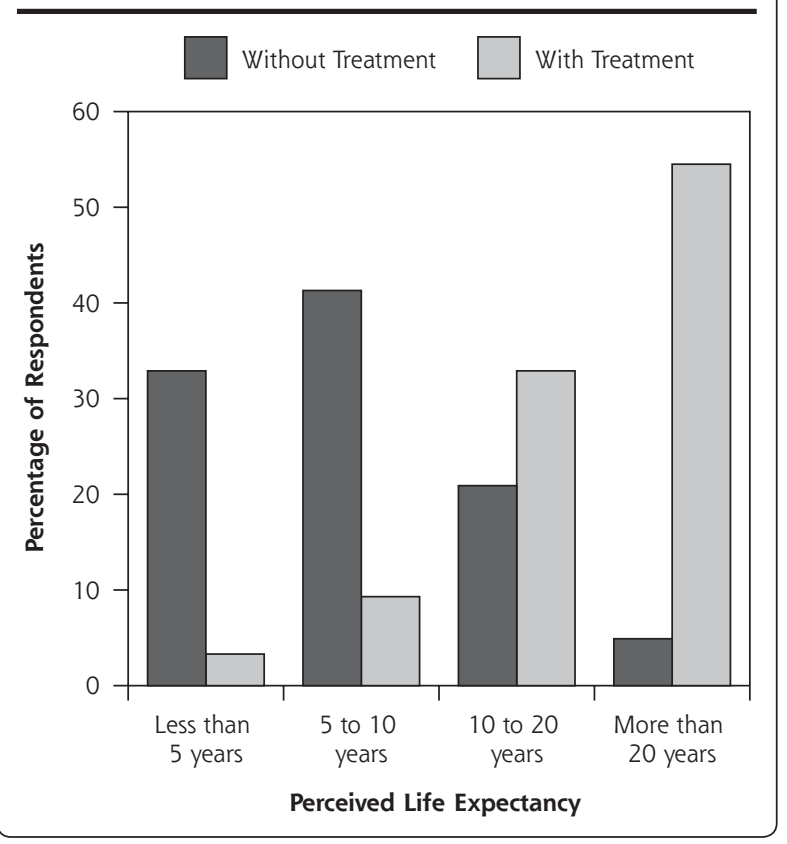

Table 2. Comparisons of Perceived Life Expectancy Outcomes Between Treatment Groups in Unadjusted and Adjusted Analyses

\begin{tabular}{|c|c|c|c|}
\hline \multirow[b]{2}{*}{ Outcomes } & \multicolumn{3}{|c|}{ Treatment } \\
\hline & Surgery & Radiation & WWIAS \\
\hline \multicolumn{4}{|l|}{ Unadjusted, mean (SD), y } \\
\hline Perceived LE without treatment & $8.01(6.3)$ & $8.13(5.4)$ & $9.97(7.5)$ \\
\hline Perceived LE with treatment & $20.30(6.7)^{b}$ & $19.38(6.6)^{c}$ & $16.66(7.1)$ \\
\hline Difference in perceived LE & $12.29(7.7)^{\mathrm{b}}$ & $11.24(7.3)^{b}$ & $6.69(7.9)$ \\
\hline \multicolumn{4}{|l|}{ Adjusted for covariates, ${ }^{a}$ mean, $y$} \\
\hline Perceived LE without treatment & 8.38 & 7.66 & 9.46 \\
\hline Perceived LE with treatment & $20.03^{c}$ & 19.59 & 17.33 \\
\hline Difference in perceived LE & $11.65^{b}$ & $11.94^{b}$ & 7.87 \\
\hline \multicolumn{4}{|c|}{$\mathrm{LE}=$ life expectancy; WW/AS = watchful waiting or active surveillance. } \\
\hline \multicolumn{4}{|c|}{ 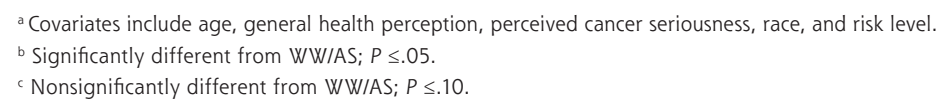 } \\
\hline
\end{tabular}

ceived difference in LE was significantly less for WW/ AS men than for men who chose aggressive treatment.

Table 3 presents the results of multiple linear regression predicting the perceived difference in LE between aggressive treatment groups and the WW/ AS group. In the final model, age, general health, perceived cancer seriousness and treatment group (surgery vs WW/AS, and radiation vs WW/AS) were significant predictors of perceived difference in LE, while race and risk level were not.

\section{DISCUSSION}

In a population-based cohort of black and white men with newly diagnosed LPC, we found that all men, regardless of age, race, education, and comorbidity, held unrealistic survival expectations of active treatment. Men who chose surgery or radiation believed they would achieve an increase in LE of more than a decade compared with not receiving any treatment, a substantial overestimate of reported years gained by these interventions. ${ }^{12,19}$ This unrealistic expectation appears to be driven by perceived (but not actual) severity of their cancer after adjustment for patient age and general health. Neither race nor tumor risk level was associated with patients' perceived increase in LE from treatment. Correcting this therapeutic misconception is critical to improving patient decision making regarding not only treatment, but also screening for prostate cancer. Therapeutic misconceptions have long been recognized to be a barrier to informed consent for clinical trials. ${ }^{20}$ We suggest, however, they are equally problematic in patient choice among treatments.

Across studies, between $86 \%$ and $98 \%$ of men diagnosed with LPC did not die from their cancer in all age and comorbidity strata. ${ }^{21}$ More than 95\% of patients with LPC live beyond 10 years after diagnosis. ${ }^{22} \mathrm{~A}$ recent update of the largest and longest-followed active surveillance cohort showed $98 \%$ and $94 \%$ prostate cancer-specific survival rates at 10 - and 15 -year follow-up, respectively. ${ }^{23}$ Only 25\% of all patients in our study, however, expected to live more than 10 years. This is of particular concern in LPC because men who choose active treatment have survival almost identical to that of those who chose observation, but active treatment is associated with high rates of impotence and incontinence. Our surgery group expected to gain 12 years of life from active treatment, while the Prostate Cancer Intervention Versus Observation Trial (PIVOT) showed that 
surgery did not significantly improve prostate cancerspecific survival compared with observation after 10 years follow-up. ${ }^{12}$

Underutilization of active surveillance has been shown repeatedly, despite strong evidence from randomized trials regarding its safety in LPC. ${ }^{12,24,25}$ In fact, the majority (72\%) of US prostate urologists and radiation oncologists believe that for low-risk LPC, active surveillance is effective but underutilized. ${ }^{26}$ Many of these same clinicians also state that their patients are not interested in active surveillance. ${ }^{26}$ Our data suggest that unrealistic survival expectations of active treatment may contribute to this lack of interest. We are not aware of any previous work that has examined

\section{Figure 2. Perceived life expectancy without treatment} and with treatment of choice, by treatment group.

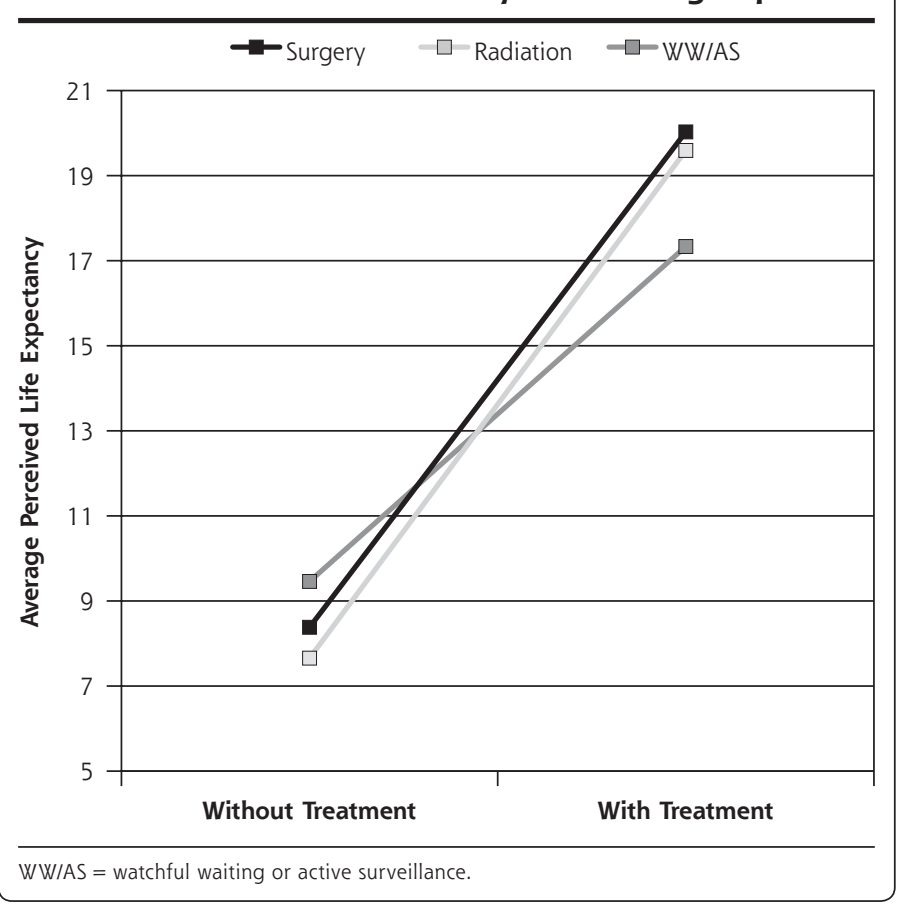

Table 3. Multiple Linear Regression Results Predicting Perceived Difference in Life Expectancy with Treatment Choice $(n=235)$

\begin{tabular}{|c|c|c|c|c|}
\hline Variable & b (95\% Cl) & SE & $\boldsymbol{\beta}$ & $P$ value \\
\hline Age & $-0.18(-0.31$ to -0.04$)$ & 0.07 & -0.18 & .01 \\
\hline Race (Black $=0$, White $=1$ ) & $-1.32(-3.24$ to 0.61$)$ & 0.98 & -0.09 & .18 \\
\hline General health perception & $1.20(0.08$ to 2.33$)$ & 0.57 & 0.14 & .04 \\
\hline Perceived cancer seriousness & $0.97(0.21$ to 1.73$)$ & 0.39 & 0.17 & .01 \\
\hline Cancer risk levela & $-0.39(-1.87$ to 1.08$)$ & 0.75 & -0.04 & .60 \\
\hline Surgery vs WWIAS & $3.77(0.50$ to 7.04$)$ & 1.67 & 0.25 & .02 \\
\hline Radiation vs WWIAS & $4.06(0.87$ to 7.25$)$ & 1.62 & 0.25 & .01 \\
\hline \multicolumn{5}{|c|}{$\begin{array}{l}\text { WW/AS = watchful waiting or active surveillance; } b=\text { Unstandardized regression coefficient; } \beta=\text { Stan- } \\
\text { dardized regression coefficient. }\end{array}$} \\
\hline \multicolumn{5}{|c|}{ a Prostate cancer risk level based on D'Amico criteria. } \\
\hline
\end{tabular}

survival misperceptions as potential drivers of treatment choice in LPC. Since physician recommendation is the primary driver of treatment choice in LPC, this has implications for research, for provider and patient education, as well as for policy and practice. . $27^{27}$

Shared decision making and better information have been shown to improve unrealistic expectations. ${ }^{28,29}$ Shared decision making and decision aids, however, presently focus on side effects of different treatments, but not LE. None of the leading prostate cancer decision aids discuss the likely survival period following diagnosis. ${ }^{28}$ Talking about LE, which is intimately related to discussions of death and dying, can be distressing to patients and physicians alike, and is uncommon in clinical practice. ${ }^{30}$ This traditional avoidance of LE discussion is a missing element in contemporary shared-decisionmaking practice. It is particularly important to good patient decision making, since one-third of healthy older adults underestimate their likely survival. ${ }^{31}$ It is likely that patients with a cancer diagnosis are even more likely to underestimate their survival.

We suggest that the problem of patient misconception of prognosis creates an opportunity for interdisciplinary and cross-specialty communication with prostate cancer patients. Urologists and radiation oncologists may have limited opportunity to establish a strong relationship with a patient in the narrow timeframe of diagnosis and treatment discussions, which can make tailoring information to the patient's needs more difficult. ${ }^{32}$ Primary care physicians, who care for patients over long periods, have the advantage of intimate knowledge of their patients' approach to clinical decision making and disease management in the course of their prior illnesses. If primary care physicians are included in the decision process following diagnosis, they could begin to focus on helping patients with LPC develop realistic expectations and make choices that support their treatment goals. While such crossspecialty counseling is not common following a LPC diagnosis, ${ }^{34}$ the special skills of primary care physicians in this expanded notion of shared decision making may provide a unique contribution to well-coordinated LPC treatment decision making.

We found that men who perceived their cancer as more serious expected more benefit from their chosen treat- 
ment regardless of their objective cancer risk level. This finding remained after adjusting for demographic factors, socioeconomic status, tumor characteristics, and comorbidities. This is an important new finding that, if confirmed, can help target interventions that support and educate men with evidence-based, unbiased information of the true risk of their cancer to improve the quality of their treatment decision. Another new but unexpected finding was that men who chose WW/AS expected to live more than 7 years longer than with no treatment. Perhaps most of these men were actually under active surveillance with the option to convert to aggressive therapy based on signs of tumor progression. In addition, monitoring itself could be seen as doing something instead of "doing nothing," which could alleviate some of the anxiety of living with untreated cancer.

This study has important strengths. Our study is 1 of a few population-based studies that have examined the effects of personal, racial, psychosocial, clinical, and treatment-choice characteristics on the survival expectations of patients with prostate cancer. The study has several limitations, however. First, it included only 31 patients who chose WW/AS. Larger studies are needed to confirm our findings related to that treatment option. In addition, we did not differentiate watchful waiting from active surveillance in this study since these terms are often used interchangeably by both physicians and patients. Second, as this survey was done between 2009 to 2010, it likely under-represents active surveillance in present practice. ${ }^{12,35,36}$ Our sample has a relatively low percentage of low-risk disease (18.6\%) compared with most published data, mainly due to the higher proportion of clinical stage T2c or higher. ${ }^{12,37,38}$ This probably does not limit generalizability, however, since recalculating risk level using only PSA and Gleason score shows the proportion of low-risk disease to be similar to that in other studies, with the perceived gain in LE for aggressive treatment unchanged. Finally, our data was from 1 geographic location, which may not be representative of other locations.

\section{Practice Implications}

We found that most men with LPC underestimated life expectancy without treatment and overestimated the gain in life expectancy with surgery or radiation. These unrealistic expectations could lead to overtreatment, decisional regret, and decreased post-treatment quality of life. There is an urgent need for interdisciplinary and cross-specialty communication with patients who have prostate cancer. In collaboration with oncology specialists, primary care physicians are often best positioned to help patient develop realistic life expectancy estimates and associated treatment goals. Given the challenges in prognostication, primary care physicians should increase their own comfort with this type of counseling and their capacity to guide patients on this complex and often intimidating journey.

To read or post commentaries in response to this article, see it online at http://www.annfammed.org/content/14/3/208.

Key words: localized prostate cancer; surgery; radiation; watchful waiting; active surveillance; survival expectation; shared decision making

Submitted July 14, 2015; submitted, revised, January 9, 2016; accepted January 28, 2016.

Funding support: This study is funded by American Cancer Society (Grant number: MRSGT-06-133-01-CPPB).

Previous presentation: Presented in part at the 2014 Annual NAPCRG Meeting; November 21-25, 2014; New York, New York.

\section{References}

1. Thompson I, Thrasher JB, Aus G, et al.; AUA Prostate Cancer Clinical Guideline Update Panel. Guideline for the management of clinically localized prostate cancer: 2007 update. J Urol. 2007;177(6): 2106-2131.

2. Mohler J, Bahnson RR, Boston B, et al. NCCN clinical practice guidelines in oncology: prostate cancer. J Natl Compr Canc Netw. 2010;8(2):162-200.

3. Hoffman KE, Niu J, Shen Y, et al. Physician variation in management of low-risk prostate cancer: a population-based cohort study. JAMA Intern Med. 2014;174(9):1450-1459.

4. Cooperberg MR, Broering JM, Carroll PR. Time trends and local variation in primary treatment of localized prostate cancer. J Clin Oncol. 2010;28(7):1117-1123.

5. Xu J, Janisse J, Ruterbusch J, Ager J, Schwartz KL. Racial differences in treatment decision-making for men with clinically localized prostate cancer: a population-based study. [published online ahead of print may 5, 2015]. J Racial Ethn Health Disparities. doi 10.1007/ s40615-015-0109-8.

6. Hamilton AS, Albertsen PC, Johnson TK, et al. Trends in the treatment of localized prostate cancer using supplemented cancer registry data. BJU Int. 2011;107(4):576-584.

7. Nguyen PL, Gu X, Lipsitz SR, et al. Cost implications of the rapid adoption of newer technologies for treating prostate cancer. J Clin Oncol. 2011;29(12):1517-1524.

8. Xu J, Dailey RK, Eggly S, Neale AV, Schwartz KL. Men's perspectives on selecting their prostate cancer treatment. J Natl Med Assoc. 2011;103(6):468-478.

9. Parker C. Active surveillance of early prostate cancer: rationale, initial results and future developments. Prostate Cancer Prostatic Dis. 2004;7(3):184-187.

10. Dall'Era MA, Cooperberg MR, Chan JM, et al. Active surveillance for early-stage prostate cancer: review of the current literature. Cancer. 2008;112(8):1650-1659.

11. Latini DM, Hart SL, Knight SJ, et al.; CaPSURE Investigators. The relationship between anxiety and time to treatment for patients with prostate cancer on surveillance. J Urol. 2007;178(3 Pt 1):826831, discussion 831-832.

12. Wilt TJ, Brawer MK, Jones KM, et al.; Prostate Cancer Intervention versus Observation Trial (PIVOT) Study Group. Radical prostatectomy versus observation for localized prostate cancer. $N$ Engl I Med. 2012;367(3):203-213. 
13. Mohan R, Beydoun H, Barnes-Ely ML, et al. Patients' survival expectations before localized prostate cancer treatment by treatment status. J Am Board Fam Med. 2009;22(3):247-256.

14. Zeliadt SB, Ramsey SD, Penson DF, et al. Why do men choose one treatment over another?: a review of patient decision making for localized prostate cancer. Cancer. 2006;106(9):1865-1874.

15. Dillman D. Mail and Telephone Surveys. New York, NY: John Wiley and Sons Inc; 1978.

16. Xu J, Neale AV, Dailey RK, Eggly S, Schwartz KL. Patient perspective on watchful waiting/active surveillance for localized prostate cancer. J Am Board Fam Med. 2012;25(6):763-770.

17. Charlson ME, Pompei P, Ales KL, Mackenzie CR. A new method of classifying prognostic comorbidity in longitudinal studies: development and validation. J Chronic Dis. 1987;40(5):373-383.

18. D'Amico AV, Whittington R, Malkowicz SB, et al. Biochemical outcome after radical prostatectomy, external beam radiation therapy, or interstitial radiation therapy for clinically localized prostate cancer. JAMA. 1998;280(11):969-974.

19. Wilt TJ, MacDonald R, Rutks I, Shamliyan TA, Taylor BC, Kane RL. Systematic review: comparative effectiveness and harms of treatments for clinically localized prostate cancer. Ann Intern Med. 2008; $148(6): 435-448$.

20. Henderson GE, Churchill LR, Davis AM, et al. Clinical trials and medical care: defining the therapeutic misconception. PLoS Med. 2007;4(11):e324.

21. Edwards BK, Noone AM, Mariotto AB, et al. Annual Report to the Nation on the status of cancer, 1975-2010, featuring prevalence of comorbidity and impact on survival among persons with lung, colorectal, breast, or prostate cancer. Cancer. 2014;120(9): 1290-1314.

22. Brenner $H$, Arndt V. Long-term survival rates of patients with prostate cancer in the prostate-specific antigen screening era: population-based estimates for the year 2000 by period analysis. J Clin Oncol. 2005;23(3):441-447.

23. Klotz L, Vesprini D, Sethukavalan $P$, et al. Long-term follow-up of a large active surveillance cohort of patients with prostate cancer. J Clin Oncol. 2015;33(3):272-277.

24. Bill-Axelson A, Holmberg L, Ruutu M, et al.; SPCG-4 Investigators. Radical prostatectomy versus watchful waiting in early prostate cancer. N Engl J Med. 2011;364(18):1708-1717.

25. Ganz PA, Barry JM, Burke W, et al. National Institutes of Health State-of-the-Science Conference: role of active surveillance in the management of men with localized prostate cancer. Ann Intern Med. 2012;156(8):591-595.

26. Kim SP, Gross CP, Nguyen PL, et al. Perceptions of Active Surveillance and Treatment Recommendations for Low-risk Prostate Cancer: Results from a National Survey of Radiation Oncologists and Urologists. Med Care. 2014;52(7):579-585.
27. Holmes-Rovner M, Montgomery JS, Rovner DR, et al. Informed Decision Making: Assessment of the Quality of Physician Communication about Prostate Cancer Diagnosis and Treatment. Med Decis Making. 2015;35(8):999-1009.

28. Stacey D, Légaré $F$, Col NF, et al. Decision aids for people facing health treatment or screening decisions. Cochrane Database Syst Rev. 2014;1:CD001431.

29. Wegwarth O, Gigerenzer G. Less is more: Overdiagnosis and overtreatment: evaluation of what physicians tell their patients about screening harms. JAMA Intern Med. 2013;173(22):2086-2087.

30. Bernacki RE, Block SD; American College of Physicians High Value Care Task Force. Communication about serious illness care goals: a review and synthesis of best practices. JAMA Intern Med. 2014; 174(12):1994-2003.

31. Romo RD, Lee SJ, Miao Y, Boscardin WJ, Smith AK. Subjective, Objective, and Observed Long-term Survival: A Longitudinal Cohort Study. JAMA Intern Med. 2015;175(12):1986-1988.

32. Davison BJ, Goldenberg SL, Gleave ME, Degner LF. Provision of individualized information to men and their partners to facilitate treatment decision making in prostate cancer. Oncol Nurs Forum. 2003;30(1):107-114

33. Mao JJ, Palmer SC, Straton JB, et al. Cancer survivors with unmet needs were more likely to use complementary and alternative medicine. J Cancer Surviv. 2008;2(2):116-124.

34. Jang TL, Bekelman JE, Liu Y, et al. Physician visits prior to treatment for clinically localized prostate cancer. Arch Intern Med. 2010;170(5): 440-450

35. Womble PR, Montie JE, Ye Z, Linsell SM, Lane BR, Miller DC; Michigan Urological Surgery Improvement Collaborative. Contemporary use of initial active surveillance among men in Michigan with lowrisk prostate cancer. Eur Urol. 2015;67(1):44-50.

36. Cooperberg MR, Carroll PR. Trends in Management for Patients With Localized Prostate Cancer, 1990-2013. JAMA. 2015;314(1): 80-82.

37. Barocas DA, Cowan JE, Smith JA Jr, Carroll PR; CaPSURE Investigators. What percentage of patients with newly diagnosed carcinoma of the prostate are candidates for surveillance? An analysis of the CaPSURE database. J Urol. 2008;180(4):1330-1334, discussion 1334-1335.

38. Cooperberg MR, Broering JM, Kantoff PW, Carroll PR. Contemporary trends in low risk prostate cancer: risk assessment and treatment. J Urol. 2007;178(3 Pt 2):S14-S19. 